\title{
DO MP3 À CONSTITUIÇÃO DO HIPERTEXTO
}

\author{
Maria Itamara Alves Garcia - UNISINOS - m.itamara@hotmail.com
}

\section{Resumo}

Este trabalho consiste na reflexão sobre o hipertexto nas relações dialógicas e complexas do ambiente educacional e dos fluxos de linguagens que surgem neste ambiente, culminando na produção de sentido. Sob o Paradigma do Pensamento Sistêmico, o referencial teórico baseia-se nas teorias de Edgar Morin e Mikhail Bakhtin. Para tal fim, será utilizada a pesquisa em andamento que visa compreender o hipertexto enquanto processo de produção de sentido em contexto multimidiático através da elaboração de blogs por alunos do nível médio em uma escola pública de Porto Alegre. Os alunos tiveram autonomia para utilizar aparelhos digitais móveis como: celular, câmera digital e os aparelhos de media player (mp3, mp4, mp5, mp6, mp7, mp8 e outros) na organização dos blogs, além do espaço da Web. A pesquisa se caracteriza como uma abordagem qualitativa de pesquisa-ação. Os resultados parciais da pesquisa estão demonstrando a importância do hipertexto e das estratégias de ensino em contexto digital.

Palavras-chave: hipertexto, produção de sentido, tecnologia digital, objeto de aprendizagem.

\begin{abstract}
This work is the reflection on the hypertext in dialogical relationships and complex environmental education and flow of language that arise in this environment, culminating in the production of meaning. Under the paradigm of systemic thinking, the theoretical framework is based on the theories of Mikhail Bakhtin and Edgar Morin. To this end, shall be used for ongoing research that aims to understand the hypertext as a process of production of meaning in context of media through the development of blogs by students at the secondary level in a public school in Porto Alegre. Students were free to use mobile digital devices such as mobile phone, digital camera and media player devices (mp3, mp4, mp5, mp6, mp7, mp8 and others) in the organization of blogs, beyond the area of Web Search is characterized as a qualitative approach of action research. The partial results of research are demonstrating the importance of hypertext and the strategies of education in the digital environment.
\end{abstract}

Keywords: hypertext, sense of production, digital technology, the object of learning.

\section{Introdução}

As tecnologias digitais, na sociedade atual, possuem uma importância fundamental e a utilização de seus recursos na educação podem representar uma abordagem de ensino e aprendizagem significativa. Unidos a este contexto, os avanços da tecnologia digital trouxeram questões que propõem o repensar da definição e do conceito de hipertexto. É necessário partir da semiótica e identificar a imagem, a música e o movimento enquanto seus formadores. A esfera do hipertexto que compõe a produção de sentido possui, além dos elementos verbais, outros como: imagem, som, animação e links. Além disso, possui uma estrutura não-linear e autoria coletiva. Este 
contexto de produção textual e de construção de conhecimento pode ser mediado pelos aparelhos digitais móveis.

Frente a este contexto desafiador, elaboramos uma pesquisa, que se encontra em andamento, e procuramos estudar os paradigmas do pensamento científico a fim de selecionar aquele que propõe refletir princípios coerentes com este trabalho, pois, segundo Foucault (1986, p. 29):

Essas formas prévias de continuidade, todas essas sínteses que não problematizamos e que deixamos valer de pleno direito, é preciso, pois, mantê-las em suspenso. Não se trata, é claro, de recusá-las definitivamente, mas sacudir a quietude com a qual as aceitamos; mostrar que elas não se justificam por si mesmas, que são sempre o efeito de uma construção cujas regras devem ser conhecidas e cujas justificativas devem ser controladas; definir em que condições e em vista de que análises, algumas são legítimas; indicar as que, de qualquer forma não podem mais ser admitidas.

O Pensamento Sistêmico, enquanto paradigma, propõe uma visão a partir de três pressupostos: a complexidade, a instabilidade e a intersubjetividade. Na dimensão da complexidade, é possível ampliar o foco de observação, partindo da rede complexa de interações percebidas até a observação do fenômeno em estudo. Este movimento sistêmico contempla o princípio da conexão universal dos objetos e fenômenos. A instabilidade, enquanto dimensão sistêmica, pressupõe a permanente transformação ao enfatizar o princípio de movimento permanente e de desenvolvimento. Por fim, a intersubjetividade, enquanto pressuposto, é enfatizada a partir da participação do pesquisador no processo de pesquisa e da importância dos sujeitos e das suas relações que aí são problematizadas.

Sob o paradigma do pensamento sistêmico, os pressupostos teóricos que orientam a reflexão sobre a pesquisa são as teorias de Edgar Morin e Mikhail Bakhtin. Morin (1988) propõe a emergência de promover o pensamento científico complexo. Segundo ele, pensar a complexidade é respeitar três princípios fundamentais: o complexo (o todo), a imprevisibilidade e a racionalidade aberta. Segundo Bakhtin (2003), a palavra não sai da gramática ou dos dicionários, ela sai dos lábios dos seres humanos, pois a consciência linguística está na heteroglossia e não na língua isolada. $\mathrm{O}$ estudo, nesta perspectiva, busca comprometer-se com as questões sociais que emergem da heteroglossia dialogizada (termos de Bakhtin).

A partir deste contexto, a compreensão do hipertexto enquanto processo de produção de sentido em contexto multimidiático, através de um diálogo entre as concepções do paradigma do pensamento sistêmico complexo de Edgar Morin e a interação dialógica do discurso de Mikhail Bakhtin, constitui o foco desta pesquisa. Como desafio, propomos compreender o hipertexto não como gênero do discurso ou suporte tecnológico, mas como processo de produção de sentido constituido na relação dialógica e na complexidade.

Este estudo caracteriza-se como uma abordagem qualitativa de pesquisa-ação de cunho histórico-sócio-antropológico. Devido a esse fato e ao contexto da pesquisa, foi escolhido o método a partir de uma perspectiva da teoria de Morin. Os procedimentos da pesquisa tiveram quatro momentos distintos: a observação participante, a produção de sentido elaborada pelos movimentos hipertextuais na organização do blog, o diário dos movimentos e a entrevista aberta.

A relevância científica deste estudo reside na reflexão sobre a importância das tecnologias digitais e seus objetos de aprendizagem enquanto mediadores na construção do conhecimento e na produção de sentido. O movimento deste repensar supõe a análise conceitual do hipertexto enquanto sistema aberto, dinâmico e complexo, e de novas formas de produção textual em meio multimodal através de uma práxis dialógica na 
intersubjetividade, de acordo com o seu contexto sócio-histórico e cultural: uma sociedade globalizada e em permanente aceleração do tempo.

$\mathrm{O}$ texto está organizado em seis partes. Na próxima parte, são focalizados os princípios epistemológicos do paradigma do pensamento sistêmico, na terceira, a teoria da complexidade de Morin, na quarta, a teoria dialógica do discurso do Círculo de Bakhtin. Na quinta parte, são descritos os procedimentos da pesquisa e os resultados parciais e, na última parte, as considerações finais.

\section{O Pensamento Sistêmico enquanto paradigma da ciência}

Segundo Morin (1998, p. 12), "a grande descoberta do século é que a ciência não é o reino da certeza". Os pilares da ciência moderna: ordem, separabilidade e lógica, reconhecidas por ela como "fundamentos absolutos", foram descartadas, respectivamente, por Laplace, Pascal e Popper. Desde então, estão sendo questionados o pensamento científico moderno e os paradigmas cartesiano, newtoniano e positivista. Morin também critica a racionalidade fechada e os paradigmas modernos. Para ele, os conceitos dominantes e suas relações "racionais" formam um paradigma de redução e de disjunção, tornando-nos cegos nesta era da globalização.

A partir das descobertas da física, podemos afirmar que a complexidade não é mais uma propriedade específica dos fenômenos biológicos e sociais, e sim, um pressuposto epistemológico transdisciplinar. A complexidade fez cair o pressuposto da simplicidade da ciência moderna. Morin (1998) propõe a emergência de um novo paradigma que promova o pensamento científico complexo. Segundo ele, pensar a complexidade é respeitar três linhas fundamentais: o complexo (o todo), a imprevisibilidade e a racionalidade aberta. Aponta Morin (1998, p.17): "Não somos seres fluidos nem sólidos. Somos híbridos que vivem à temperatura de sua combustão e destruição". O pressuposto da complexidade também é descrito por Morin através dos princípios da contextualização do objeto, do foco nas relações de seus elementos, da operação lógica de conjunção ou integração, da dialógica dos conceitos antagônicos que se relacionam e se complementam em um sistema, das relações casuais recursivas (que não tem a ver com a retroação dos sistemas auto-reguladores, e, sim, com os processos em que os efeitos são necessários àquele que o gera), de não negar ou reduzir a contradição e da relação hologramática (o todo está nas partes e elas estão no todo, não se pode conhecer as partes sem conhecer o todo e vice-versa).

Nesse aspecto, o hipertexto em uma relação possível com a teoria de Morin caracterizar-se-ia pela não-linearidade através da complexidade, da instabilidade, da intersubjetividade e da relação dialógica de seus elementos, definindo-se como um sistema complexo. Esta é a proposta que queremos desenvolver neste trabalho.

Segundo Vasconcellos (2008), a instabilidade fez cair o pressuposto epistemológico da estabilidade da ciência moderna. Entre as teorias que contemplam a instabilidade está a Termodinâmica. Essa teoria preocupa-se com o movimento da energia e como a energia cria o movimento. As leis da termodinâmica postulam que a energia pode ser transferida de um sistema para outro. Em 1865, Clausius formulou a segunda lei da termodinâmica. Esta lei postula que a quantidade de entropia (grandeza termodinâmica que corresponde ao grau de desordem ou caos) aumenta seu valor com o tempo e que, na interação de uma parte do sistema com outra parte, a energia tende a se dividir buscando o equilíbrio. Esta lei foi chamada de Lei da Entropia. É interessante mencionar que esta lei foi elaborada após seis anos da publicação de Darwin, "A Origem das Espécies", e que a palavra entropia significa "evolução" em grego. Ela foi aceita entre os cientistas; entretanto, eles não entenderam a potencialidade da segunda lei da termodinâmica. Somente na segunda metade do século XX, com Prigogine, a Lei 
da Entropia foi estudada profundamente. Prigogine descobriu que a entropia pode crescer o seu valor durante um processo natural de um sistema (vivo ou não), de uma forma espontânea e em um único sentido. Este movimento é irreversível, por isso, a entropia, segundo Prigogine, também é chamada de "flecha do tempo". Desde então, podemos pensar que, ao se consumir energia, aumenta-se a entropia no universo. Esta é irreversível e dinâmica, ou seja, o tempo avança na direção do aumento da desordem, do caos.

De acordo com Prigogine (1984), as estruturas dissipativas são sistemas nãolineares e instáveis, na qual o caos leva a novas formas de comportamento e estruturas diferentes das formas anteriores. Para o autor, a instabilidade, a desordem e a imprevisibilidade são fatores preponderantes nessas novas formações, às vezes mais complexas na sua organização. Para ele, nos sistemas em equilíbrio, ou seja, nos sistemas lineares, as flutuações se contrabalançam. Entretanto, quanto mais longe do equilíbrio, os sistemas mostram-se instáveis, em desequilíbrio, ou seja, não-lineares, pois as flutuações não se contrabalançam. As flutuações são incessantes e inevitáveis nos sistemas. Elas têm origem interna e externa. As internas são geradas espontaneamente; enquanto que, as externas são causadas por um ambiente com fortes flutuações ocorridas ao acaso, apresentando uma perturbação (crise). Em um ponto de bifurcação, uma flutuação de uma região do sistema pode invadir o todo e fazê-lo saltar de uma forma de funcionamento para outra inesperada. Chama-se "salto qualitativo". O sistema deixa o seu curso natural e escolhe, entre as alternativas disponíveis, uma nova forma de funcionamento. Surge, então, a nova ordem de um processo de autoorganização. Prigogine (1984) afirma que essa escolha é influenciada por escolhas anteriores realizadas em caminhos anteriores trilhados, por isso prever a evolução dos sistemas já não é mais instantâneo, mas pode ser baseado no comportamento das bifurcações anteriores. O reconhecimento da "desordem" nos estudos científicos exige uma nova forma de pensamento: a inclusão da indeterminação e da imprevisibilidade. $\mathrm{O}$ movimento de um sistema, após uma perturbação indeterminada, torna-se indeterminado, não-linear e, consequentemente, imprevisível. Portanto, o tempo está associado à evolução e à auto-organização. Os princípios que eram vistos como "desvios" passam, agora, a serem reconhecidos como condição necessária para a evolução.

As características da indeterminação e da imprevisibilidade estão constituídas no processo hipertextual. $\mathrm{O}$ fator de instabilidade é desencadeado pela imprevisibilidade e pela indeterminação da ação do sujeito leitor/autor na comunicação discursiva e pela organização do programa que constitui a não-linearidade do sistema aberto. No hipertexto, uma nova ordem surge a partir dos hiperlinks acessados. Comparando os dois contextos, podemos pensar da seguinte forma: no hiperlink (ponto de bifurcação), o sujeito/leitor poderá clicar (a ação enquanto flutuação) e invadir o hipertexto (o todo) e fazê-lo saltar de uma forma (ordem) para outra (ordem). Ele deixa a sua ordem atual (seu curso natural) e escolhe, entre os hiperlinks (alternativas) disponíveis, uma nova ordem (organização) conforme os diferentes pontos de conexões possíveis através da ação de lincar do sujeito/leitor.

Descrever o pressuposto da intersubjetividade é passar, obrigatoriamente, pelo âmbito da linguagem que, por sua vez, passa pelo âmbito social. Morin (1996) aponta como oitava avenida da complexidade a volta do observador na sua observação. $O$ observador está no objeto de observação, assim como o objeto de observação está no observador (princípio hologramático). Para ele, visualizar a contextualização do objeto de estudo é fundamental. Todos os elementos e suas relações fazem parte deste 
contexto, inclusive o próprio sujeito/observador. A intersubjetividade é a pluralidade de sujeitos que estão inseridos no contexto do objeto de estudo.

\section{Edgar Morin e a Teoria da Complexidade}

Segundo Morin (1996), a ciência deve assumir a complexidade. Ele afirma que um sistema não é totalitário e hierárquico do todo. Ele é aberto às politotalidades. Segundo ele, as relações todo-partes devem ser mediadas pelas interações, que são as ações entre as unidades complexas. A idéia de organização emergiu nas ciências sob o nome de estrutura, mas esta palavra só remete a idéia de ordem. A organização é ativa. Ela cria a ordem e a desordem e pode produzir a entropia (degradação) ou a neguentropia (regeneração). Para Morin,

Complexus significa o que foi tecido junto; de fato, há complexidade quando elementos diferentes são inseparáveis constitutivos do todo (como o econômico, o político, o sociológico, o psicológico, o afetivo, o mitológico), e há um tecido interdependente, interativo e inter-retroativo entre o objeto de conhecimento e seu contexto, as partes e o todo, o todo e as partes e as partes entre si. Por isso a complexidade é a união entre a unidade e a multiplicidade. Os desenvolvimentos próprios da nossa era planetária nos confrontam cada vez mais e de maneira cada vez mais inelutável com os desafios da complexidade (MORIN, 1996, p. 38).

Para o autor (1996, p.83), “o objetivo do conhecimento não é descobrir o segredo do mundo numa equação mestra da ordem que seria equivalente à palavra mestra dos grandes mágicos. O objetivo é dialogar com o mistério do mundo". Por isso é importante trabalhar com a incerteza e o diálogo com a irracionalidade, pois a complexidade é pensar conjuntamente os conceitos antagônicos. O princípio dialógico permite a dualidade de noções eventualmente antagônicas, mas que se constituem complementares. A relação dialógica permite a dualidade em si, afastando uma possível síntese dialética. No caso do campo de problematização deste estudo, o hipertexto não tem sequência e topicidade definida. A noção de coerência não cabe em seu contexto. Entretanto, ele liga textos não necessariamente correlacionados. Estas características do hipertexto expressam que os seus elementos estão constituídos em uma relação dialógica, pois não são coerentes, mas são relevantes.

O princípio hologramático postula que o todo está nas partes, assim como as partes estão no todo. Não no sentido reducionista ou holístico, mas no sentido dialógico. Morin utiliza a palavra holograma devido a sua imagem possuir as mesmas características, tanto no todo, quanto em suas partes. Esta relação constitui uma contradição. Na ciência clássica, a contradição indica sinal de erro lógico, pois ela imobiliza o sistema linear. Entretanto, na teoria da complexidade, a contradição é reconhecida como parte do sistema e suas relações consideradas como dialógicas. No hipertexto, a hologramaticidade encontra-se em sua característica de intertextualidade através da relação dialógica da autonomia e da interdependência de seus textos em uma estrutura rizomática. Também é possível comparar este princípio com a característica de fragmentaridade (no sentido de parte do todo) do hipertexto, devido à ausência de um centro regulador. $\mathrm{O}$ autor do hipertexto não controla o tópico e o leitor, por sua vez, controla e organiza os textos acessíveis a ele.

Morin (1996) defende o movimento de causalidade circular recursiva nos sistemas. Contudo, é importante diferenciar causalidade circular recursiva da retroativa. A recursão é mais complexa do que a retroação. Na causalidade circular retroativa, o movimento é linear e o sistema é auto-regulado por um mecanismo de retroalimentação. Nesse aspecto, existe uma diferença com relação ao movimento de causalidade circular 
recursiva. Segundo Morin (1996, p. 123), "são os processos em que os efeitos e os produtos são necessários ao próprio processo que o gera. $\mathrm{O}$ produto é produtor daquilo que o produz. E embora nomeado como circular, trata-se de um movimento espiral em que ora é produto, ora é produtor". No hipertexto, o princípio recursivo é encontrado na sua capacidade de auto-organização. Por ser um sistema aberto, possui características de recursividade que promovem uma nova ordem em seu processo hipertextual. Também no hipertexto, a recursividade pode ser expressa através de sua característica multimodal, que permite conectar simultaneamente as linguagens verbais e não-verbais de forma integradora e com enunciações interpostas ao mesmo tempo, em um sentido hologramático.

De acordo com Morin (1996), a complexidade é dialógica pela junção de conceitos que lutam entre si e que formam sua totalidade. Para ele, a ordem e a desordem permanecem conjuntamente. A ordem é relativa e relacional e a desordem é incerta. As duas são faces de uma realidade e, ao mesmo tempo, são complementares e antagônicas. Como afirma Morin (1996, p. 202), "devemos considerar a ordem e a desordem nas organizações sistêmicas, pois um mundo absolutamente determinado, tanto quanto um completamente aleatório, é pobre e mutilado; o primeiro, incapaz de evoluir, e o segundo, de nascer". A ordem e a desordem juntas organizam o universo. A volatilidade do hipertexto contempla o princípio da imprevisibilidade, pois as escolhas do sujeito autor/leitor com relação às conexões acessadas são passageiras, irreversíveis e atualizadas. A instabilidade está ligada à imprevisibilidade: o hipertexto não possui, aparentemente, a estabilidade do texto impresso.

Todo o conhecimento é um processo auto-eco-organizador. A construção do conhecimento faz-se a partir do autoconhecimento. O processo auto-eco-organizado é a capacidade de uma organização sistêmica de transformar-se e reorganizar-se. $\mathrm{O}$ pensamento ecologizante proposto por Morin (1996) sustenta uma relação inseparável entre o ser humano, o conhecimento e o ambiente (cultural, social, político e natural). $\mathrm{O}$ ser humano necessita da relação com o ambiente, com outros seres humanos e consigo mesmo para se conhecer e se transformar, num movimento de auto-eco-conhecimento. Este ser humano torna-se sujeito quando passa a ser o autor de seu processo organizador. A busca da auto-organização se dá através da construção de sua autonomia. Esta, segundo Morin, deve ser nomeada por autonomia-dependência, já que se trata de uma relação dialógica necessária na dualidade antagônica e complementar.

A auto-organização do hipertexto pode ser evidenciada pelas suas características de instabilidade através da indeterminação e da imprevisibilidade, seja pela organização do programa ou pela indeterminação da ação do sujeito leitor/autor. Também através da não-linearidade do hipertexto é possível compreender a sua autoorganização, já que a sua constituição textual plurilinearizada permite saltos qualitativos e a organização de novas ordens através das vias direcionadas pelos hiperlinks.

\section{O Círculo de Bakhtin e a Teoria Dialógica do Discurso}

Segundo o Círculo de Bakhtin (1988, p. 31), o signo linguístico é um produto ideológico. Para ele, o conceito de ideologia equivale ao conceito de cultura. Um signo pode refletir (reproduzir) a cultura ou pode refratar (alterar) esta mesma cultura, ressignificando-a. Para o Círculo de Bakhtin, esta característica é tão fundamental que sem a cultura o signo não existe. Por isso, ele o nomeia de signo ideológico. A ideologia é o reflexo das relações de poder em um contexto sócio-histórico e cultural determinado 
e possui caráter semiótico, de criatividade e de compreensão. A criatividade ideológica refrata a sua realidade específica, pois existe uma diversidade cultural. Entretanto, quem dá a definição comum a todos os fenômenos é o seu caráter semiótico. No caráter da compreensão, busca-se defini-lo como "uma resposta a um signo por meio de signos", isto é, o que existe é o deslocamento, a qual a cadeia, "de signo em signo para um novo signo, é única e contínua. (...) em nenhum ponto a cadeia se quebra".

Segundo Fraga (2006), a palavra hipertexto exprime a idéia de escrita/leitura nãolinear. Possui textos variados (verbais e não-verbais) na forma de hiperlinks, cujo o acionamento se faz tocando o mouse. Estes hiperlinks trazem em seu bojo textos com signos que, muitas vezes, refratam, alternando o percurso de leitura. Esta característica propõe a não-linearidade do texto. $\mathrm{O}$ signo em questão, transcende a dimensão unitária (linear e sequencial) que é imposta pela ideologia, constituindo-se de multidimensões através do relacionamento sequencial e do acesso de múltiplas idéias. O hipertexto, este conjunto de textos verbais e não-verbais formados por uma pluralidade de signos com propósitos de refletir e de refratar as escrituras (textos escritos, poemas), as imagens (fotos, gravuras, desenhos), os sons (músicas, falas, ruídos) e sons/imagens (vídeos), é composto por signos ideológicos. Muitos são responsáveis pelas refrações, novos significados que ocorrem no processo hipertextual e que, através da desordem e da nãolinearidade, acabam fundando uma nova ordem (o que não deixa de ser linear para ela mesma). Nesse sentido, podemos concluir, então, que os textos não-verbais, quando constituidos de sentido, não necessitam da palavra, muitas vezes, e estão sempre ligados às manifestações verbais. Esse aspecto pode ser comprovado na característica multimodal do hipertexto, o que possibilita estabelecer a conexão simultânea entre a linguagem verbal e a não-verbal de forma integradora, pois segundo as concepções do Círculo de Bakhtin (1988, p. 37-38),

os processos de compreensão de todos os fenômenos ideológicos (um quadro, uma peça musical, um ritual ou um comportamento humano) não podem operar sem a participação do discurso interior. Todas as manifestações da criação ideológica, todos os signos não-verbais, banham-se no discurso e não podem ser nem totalmente isoladas nem totalmente separadas dele. (...) Nenhum dos signos ideológicos específicos, fundamentais, é inteiramente substituível por palavras. (...) Nenhum signo cultural, quando compreendido e dotado de um sentido, permanece isolado: torna-se parte da unidade da consciência verbalmente constituida.

Uma das características do hipertexto é quanto à sua espacialidade topográfica. O espaço hipertextual, a princípio, é ilimitado. Ele continua na rede em processo, mesmo que o sujeito autor/leitor desligue o computador. Nesse caso, podemos afirmar que nessa forma textual o sujeito não é o determinante, e, sim, o meio em que ele está inserido, de acordo com a teoria do Círculo de Bakhtin. Nesse contexto, é possível avaliar a importância do signo linguístico que poderá refletir (reproduzir a ordem vigente) ou refratar (ressignificar a ordem ) com possibilidades de abrir a oportunidade para o estabelecimento de uma nova ordem. Importante lembrar aqui que o "signo possui duas faces como Jano" (1988, p. 47). A ordem, em questão, representa os interesses dominantes (sociais e culturais) daquele momento. Nesse sentido, podemos comparar as concepções do Círculo de Bakhtin com as concepções de Morin e do Pensamento Sistêmico. O que ele nomeou como a organização da evolução do signo, poderia ser considerado como a organização de um sistema aberto com características de auto-organização, como o hipertexto.

Um dos pressupostos básicos na teoria de Bakhtin é a interação verbal cuja realidade fundamental é o seu caráter dialógico. Toda enunciação é um diálogo que faz parte de um processo ininterrupto. $\mathrm{O}$ enunciado reflete todos aqueles que o antecederam e aqueles que o sucederão. É um elo de cadeia que pode ser compreendido no interior 
desta cadeia. No hipertexto, podemos identificar o dialogismo através de sua característica de intertextualidade. Através dos hiperlinks, podemos ter acesso a muitos textos na rede. Esta intertextualidade permite uma relação dialógica entre os discursos, pois em cada texto estão constituidas vozes que foram elaboradas a partir de uma heteroglossia dialogizada. Também podemos comparar as idéias do Círculo de Bakhtin com as características de interatividade e iteratividade do hipertexto, as quais são definidas através das relações dialógicas que mantêm entre sujeito autor/leitor e textos; e entre textos e suas partes. Para ele (1988, p. 33), "cada signo ideológico é não apenas um reflexo, uma sombra da realidade, mas também um fragmento material dessa realidade". É impossível, diante desse enunciado, não fazer uma comparação com a teoria de Morin, que defende a complexidade através do princípio hologramático e dialógico. Sendo interessante pontuar o princípio dialógico, o qual ambos defendem enquanto pressuposto de suas teorias. Entretanto, o termo "dialógico" difere para esses autores. O sentido dialógico, para Morin, refere-se à dualidade de conceitos antagônicos e complementares, enquanto que para Bakhtin, refere-se à relação dinâmica de múltiplas inter-relações responsivas entre posições socioaxiológicas.

A interação verbal de Bakhtin está na alteridade, para ele (2003) "ser significa ser para um outro, e por meio do outro, ser para si mesmo". Decorre do principio de que é no reconhecimento do outro que os indivíduos constituem-se como sujeitos. A alteridade está intimamente relacionada com a concepção de dialogismo de Bakhtin. Para ele, o conhecimento não se encontra no interior de uma única pessoa, mas está no processo de interação dialógica entre pessoas que o relacionam de forma coletiva. Uma das características fundamentais do dialogismo é conceber a unidade do mundo nas múltiplas vozes que participam desse diálogo, ou seja, a unidade do mundo na concepção de Bakhtin é polifônica. Segundo Faraco (1988), esta heteroglossia dialogizada se caracteriza por constituir um conjunto múltiplo e heterogêneo de vozes ou línguas sociais em contínuo processo de encontros e desencontros, de aceitação e recusa, de absorção e transmutação das vozes sociais.

Segundo o Círculo de Bakhtin (1988), o discurso interior, que é constituido do social e do cultural, possui o limite de acordo com a construção cultural do falante. $\mathrm{O}$ hipertexto não pode ser considerado infinito e ilimitado, pois a constituição cultural do sujeito autor/leitor tem a capacidade de limitá-lo. Entretanto, concordamos com o Círculo de Bakhtin quando exemplifica a cadeia de enunciações como ilhas em um oceano. O hipertexto, este "oceano" de signos (a expressão da heteroglossia dialogizada), é onde se constroem os enunciados (como ilhas que emergem) de acordo com a constituição cultural daqueles que constituem a autoria coletiva. O falante, assim como o sujeito/autor do hipertexto, possui apenas parte da palavra, pois esta parte está em uma zona fronteiriça. No hipertexto, o sujeito/autor interage com a organização hipertextual que, por sua vez, tem relação com a organização do sistema em si que foi constituido por uma realidade socio-histórica e cultural determinada. Nesta realidade encontramos a pluralidade de vozes, compondo, assim, a autoria coletiva, pois o processo hipertextual reflete não somente a voz do sujeito/navegador daquele momento, mas muitas outras vozes daqueles que já passaram e deixaram marcas e daqueles que virão para fazer o mesmo.

De acordo com Bakhtin (2003, p. 280), "o primeiro e mais importante critério de conclusividade do enunciado, é a possibilidade de responder a ele, em termos mais precisos e amplos, de ocupar em relação a ele uma posição de compreensão responsiva". A "intereza" do enunciado, ou seja, o "tudo dito", é composto por três elementos ou fatores (Bakhtin, 2003, p. 281-282): a exauribilidade do objeto e do sentido, o projeto de discurso ou vontade de discurso do falante e as formas típicas 
composicionais e de gênero do acabamento. Segundo Bakhtin (2003), todo o enunciado é um "elo de cadeia" da comunicação discursiva através da posição ativa do falante com relação ao objeto e o sentido que, por sua vez, caracteriza o conteúdo semântico-objetal que se efetua em dois momentos: no primeiro, através da determinação da composição e o estilo e, no segundo, o elemento expressivo o qual determinou o primeiro.

No processo enunciativo do hipertexto, o sujeito/autor, dotado de uma vontade discursiva, acessa hiperlinks (escreve textos/produz sentido); paralelamente a esta ação, este mesmo sujeito é sujeito/leitor na medida em que lê as marcas (ou cartografias) produzidas por ele. $\mathrm{O}$ autor organiza o hipertexto de acordo com suas escolhas, deixando-as disponíveis para a leitura. Com relação ao leitor no hipertexto, este torna-se também autor no momento em que organiza e seleciona o que será lido. $\mathrm{O}$ autor no hipertexto tem importância e uma contribuição muito significativa. Apesar de suas limitações quanto a prever os tópicos e não assegurar a sua leitura, o autor será sempre produtor da ideologia produzida em seu contexto sócio-histórico e cultural, ou seja, ele é um sujeito ativo nessa relação dialógica. O leitor, apesar de possuir uma compreensão responsiva ativa e, ao mesmo tempo, controlar o que será lido no hipertexto, não pode ser considerado superior, pois ele é quem irá limitar a leitura do hipertexto, segundo as suas condições. Ele também é um sujeito ativo, com característica sócio-histórica e cultural determinada, atuante nesta relação dialógica, assim como o autor.

Na obra de Bakhtin, "Hacia una Filosofia del acto ético (1997)", estão as noções de evento, ato e acontecimento que defendem uma filosofia da ação responsável, ou seja, o sujeito é responsável e copartícipe do contexto em que ele e os outros estão inseridos e tem um compromisso inevitável com o outro "concreto". Segundo Faraco (2008, p. 50), no processo de autoria, devemos proporcionar condições para que o sujeito saia de uma consciência linguística; para Bakhtin, ptolomaica. Faraco descreve esta consciência como plurivocal; entretanto, ela "não se percebe como tal e está dogmaticamente dominada por vozes sociais incapazes de se verem pelos olhos de outras vozes do plurilinguismo". Bakhtin propõe a sua substituição pela consciência galileana, como aponta Faraco, "uma consciência linguística relativizada capaz de se ver pelos olhos da bivocalidade, pelo mútuo aclaramento crítico das vozes sociais".

\section{Os procedimentos da pesquisa e os resultados parciais}

A pesquisa que trata este artigo, caracteriza-se como uma abordagem qualitativa de pesquisa-ação de cunho histórico-sócio-antropológico, a qual possibilita a interpretação de dados, acontecimentos, comportamentos e atitudes dentro do contexto em que está inserida. Os instrumentos da pesquisa foram: a observação participante, a entrevista aberta, o diário dos movimentos hipertextuais e o blog. Devido ao contexto de pesquisa, foi escolhido o método a partir da perspectiva teórica de Morin. Contudo, apesar de Bakhtin não ter elaborado uma metodologia, também buscamos orientar a pesquisa a partir de sua perspectiva:

Devo identificar-me com o outro e ver o mundo através de seu sistema de valores, tal como ele o vê, devo colocar-me em seu lugar, e depois, de volta ao meu lugar, completar seu horizonte com tudo o que se descobre do lugar que ocupo, fora dele; devo emoldurá-lo, criar-lhe um ambiente que o cabe, mediante o excedente de minha visão, de meu saber, de meu desejo e de meu sentimento (BAKHTIN, 2003, p. 45).

Os participantes da pesquisa são os alunos do nível médio de uma escola pública de Porto Alegre. Com o objetivo de construir um espaço de avaliação do conhecimento na disciplina e de elaborar a pesquisa, a pesquisadora e professora propôs, juntamente 
com seus alunos, a produção de sentido através da construção de um blog individual. Após o estudo inicial sobre o conteúdo da disciplina, os alunos interagiram no laboratório de informática da escola com o objetivo de organizarem seus blogs. $\mathrm{O}$ contexto multimidiático em que foram elaboradas as produções textuais foi constituído pela sua diversidade de instrumentos disponíveis para este fim e pela variedade de textos, caracterizando-o como multimodal. Foi utilizado apenas uma rede de blogs, a fim de uni-los e relacioná-los, para que todos tivessem facilidade de acesso aos blogs dos colegas. Cada aluno teve a liberdade de utilizar o aparelho digital móvel que possuía e também utilizar os aparelhos dos colegas, segundo seus interesses e preferências. Na elaboração dos blogs os alunos utilizaram aparelhos digitais móveis como: celular, câmera digital e os aparelhos de media player (mp3, mp4, mp5, mp6, $\mathrm{mp} 7, \mathrm{mp} 8$, etc.), além do espaço da Web, inclusive utilizando espaços físicos dentro e fora da escola. Entre os movimentos hipertextuais processados, os blogs foram constituídos por: produções de escrita, vídeos, fotos, gravuras, músicas, textos tirados da Web, links de textos sobre o tema, versos pessoais, citações e outros componentes.

Os resultados parciais da pesquisa em andamento foram surpreendentes: os critérios da avaliação da disciplina tiveram que salientar mais o processo de construção de conhecimento, que o resultado final, pois a cada dia, os alunos ressignificavam suas produções. Pediram para continuar nas férias e utilizar o blog ao longo do curso. E a atividade pedagógica que, inicialmente tinha o objetivo de sistematizar e avaliar o conhecimento construído, transformou-se em um processo contínuo de construção de conhecimento e de informação.

\section{Considerações finais:}

Snyder (1992) define duas categorias de hipertexto: o exploratório e o construtivo. O hipertexto exploratório caracteriza-se por manter sua autoria original e enfatizar a função do leitor enquanto explorador do conhecimento. Esta categoria pode ser exemplificada, principalmente, através da literatura hipertextual. Quanto ao hipertexto construtivo, é caracterizado pela autoria coletiva e a multimodalidade com ênfase na ação do sujeito escritor/leitor que é capaz de "produzir seu próprio corpo de conhecimentos" (produção de sentido). Nesse aspecto, as tecnologias digitais possuem uma importância fundamental na construção do conhecimento, podendo mediar a constituição do hipertexto enquanto processo de produção de sentido. Através do hipertexto constituído, principalmente pelos aparelhos digitais móveis, a produção textual encontra potencialidades multimodais, o que possibilita o enriquecimento de alternativas de ensino e aprendizagem. Segundo Lemos (1999), o espaço digital pode oportunizar, além da democratização do conhecimento, do resgate do espaço urbano e das relações sociais, novas formas de fazer político. Através da democratização dos meios de comunicação favorecidos pelas tecnologias digitais, torna-se possível colocar os problemas dos cidadãos de forma coletiva, ao incentivar o debate e a tomada de posição política, cultural e social. Para isso, é importante a valorização da complexidade dos espaços virtuais que enfatizam a relação dialógica, como os espaços que retratam a realidade e seus conflitos ao incentivarem a reflexão sobre eles, como os fóruns, chats, blogs alternativos e outros que sustentem formas de comunicação livres e democráticas.

\section{Referências Bibliográficas}

BAKHTIN, M. Marxismo e filosofia da linguagem. São Paulo: Hucitec, 1988.

BAKHTIN, M. Hacia una filosofia del acto ético. De los borradores y otros escritos. Barcelona: Anthropos, 1997. 
BAKHTIN, M. Estética da criação verbal. São Paulo: Martins Fontes, 2003.

BAKHTIN, M. Problemas da poética de Dostoiévski. Rio de Janeiro: Forense Universitária, 2008.

FARACO, C. A. Uma introdução a Bakhtin. Curitiba: Hucitec, 1988.

FARACO, Carlos A. Pesquisa aplicada em linguagem: alguns desafios para o novo milênio. Delta, São Paulo, v. 17. Especial, 2001.

FOUCAULT, M. A arqueologia do saber. Rio de Janeiro: Forense-Universitária, 1986.

FRAGA, Dinorá M. Entre a não-linearidade hipertextual e a noção de arbitrariedade.

Revista Educação e Tecnologia, v. 11. n. 2, p. 33-42, jul.-dez. 2006.

FRAGA, D.; FLORES, T. Hipertexto: que texto é esse? Trabalhos em Linguística Aplicada, Campinas, n. 44(1), p. 115-132, jan.-jun. 2005.

LEMOS, André. Ciberespaço. Cibionte e inteligência coletiva?In: FRAGA, D.; VIEIRA, R. (Orgs.). Ciências cognitivas em semiótica e comunicação. São Leopoldo, UNISINOS, 1999.

MARCUSCHI, L. A.; XAVIER, A. C. (Orgs.). Hipertextos e gêneros digitais. Rio de Janeiro: Lucerna, 2004.

MORIN, E. Introdução ao Pensamento Complexo. Lisboa: Instituto Piaget, 2007.

MORIN, E. Ciência com consciência. Rio de Janeiro: Bertrand, 1996.

MORIN, E. Complexidade e Liberdade. Ensaios THOT - Associação Palas Athena, São Paulo, n. 67, p. 12-19, 1998.

MORIN, E. A Cabeça Bem-Feita: repensar a reforma, reformar o pensamento. Rio de Janeiro: Bertrand, 2006.

PRIGOGINE, I. O fim das certezas: tempo, caos e as leis da natureza. São Paulo: UNESP, 1984.

SNYDER, Ilana. Hipertext. The electronic labirinth. Washington: Melbourne University Press, 1992.

VASCONCELlOS, M. J. E. Pensamento Sistêmico: o novo paradigma da ciência. Campinas: Papirus, 2008. 
